\title{
Evaluation of Long-day Onions for Resistance to White Rot Infection Using Greenhouse and Laboratory Techniques
}

\author{
Marilyn H.Y. Hovius and Irwin L. Goldman' \\ University of Wisconsin, Madison, Department of Horticulture, 1575 Linden Drive, Madison, WI 53706
}

Additional Index words. Allium cepa, white rot, disease screening, roots, bulbs

\begin{abstract}
Breeders have found field screening for onion white rot resistance to be unreliable since consistently moderate to high disease levels that significantly differentiate cultivars, do not occur over field sites and years. The objective was to see if a greenhouse or laboratory technique could predict field reaction of onion accessions. Onion (Allium cepa) accessions were grown in fields naturally infested with the white rot causing fungus (Sclerotium cepivorum) in 1999 and 2000 (New Zealand) and in 2000 and 2001 (Canada). The field disease levels were low at three sites, moderate at two and high at one. Field screening was not a reliable predictor of white rot reaction when disease incidence was low. Onion accessions were screened for resistance in the greenhouse using nonsterile muck soil (NSMS) and sterile muck soil (SMS) with S. cepivorum sclerotia as the inoculum source. Total disease incidence was significantly higher in the NSMS compared to the SMS and accessions showed significant variability for white rot reaction in both soils. Two laboratory-based techniques were used to test the effect of onion volatiles on mycelium growth in culture. The volatiles from susceptible accessions resulted in faster radial growth of $S$. cepivorum mycelium (on water agar) and height of aerial mycelium (on potato dextrose agar) than volatiles from resistant accessions. Disease incidence in the greenhouse, $S$. cepivorum culture growth rates on water agar media and aerial mycelial height were all good predictors of field disease incidence in a covariance analysis. The best predictor was aerial mycelial height, which was predictive of field disease incidence in four out of six field sites. Onion breeders can use the methods described in this study in breeding for white rot resistance.
\end{abstract}

Sclerotium cepivorum (Berk), the cause of Allium white rot, is a fungus that is pathogenic only on members of the genus Allium. White rot occurs in almost all Allium production areas and is a serious threat to the Allium industry worldwide. In commercial onion (Allium cepa L.) production, crop losses in particularly bad years have been estimated at 30\% to $70 \%$ in New Zealand (Stewart and Fullerton, 1998), over 65\% in Ontario, Canada (Earnshaw et al., 2000) and at 100\% in Mexico (Perez-Moreno et al., 1998). Mature sclerotia of S. cepivorum, past constitutive dormancy, serve as primary inoculum. The optimum environmental conditions are soil temperatures between 9 and $20^{\circ} \mathrm{C}$ (Walker, 1924) and available soil moisture, equivalent to a matric potential of -300 mba (Crowe and Hall, 1980).

The sclerotia are stimulated to germinate by organosulfur root exudates of Allium species (Coley-Smith, 1960) and subsequent plant infection occurs. The rind of the sclerotia weakens, cracks open and the mycelium emerges from the sclerotia. Upon sclerotial germination, a hyphal plug of compact mycelium emerges through the cracked sclerotia rind leaving a hollow shell (Crowe and Hall, 1980; Sommerville and Hall, 1987). Profuse white mycelium develops and grows through the soil matrix up to $3 \mathrm{~cm}$ (Crowe and Hall, 1980) until contact with host tissue (Walker, 1924). If root infection does not occur within 10 to $14 \mathrm{~d}$, the mycelium from the germinated sclerotia dies and decays (Crowe and Hall, 1980; Coley-Smith, 1960).

After root penetration, the mycelium grows inter- and intra-

Received for publication 28 Apr. 2003. Accepted for publication 15 Oct. 2003. The technical assistance of Nick Breitbach and Kathleen Quast is gratefully acknowledged. Many thanks to the research team at the Muck Crops Research Station (Holland Marsh, Ontario, Canada) and to Scott Hendricks (Seminis Vegetable Seed, Woodland, Calif.) for their assistance with the field trials and to Scott Hendricks for supplying the onion seed. Thank you to Brian Yandell (University of Wisconsin, Departments of Horticulture and Statistics) for statistical advice. This research was supported in part by funding from Seminis Vegetable Seeds (Woodland, Calif.).

‘To whom reprint requests should be addressed; e-mail ilgoldma@wisc.edu. cellularly through the cortex to root vascular elements and to the vascular elements of stem and leaf bases causing complete death of phloem and parenchyma cells (Abd-El-Razik et al., 1973). Extensive host cell death results in localized collapse of the tissue around infection points and characteristic rot of this disease (Stewart et al., 1989). The progressive invasion by $S$. cepivorum within Allium tissues is a result of cell wall degrading enzymes produced by the fungus (Abd-El-Razik et al., 1973). Hyphae serve as secondary inoculum resulting in secondary spread of $S$. cepivorum, from plant to plant by root contact among plants of close proximity. Secondary spread by this means is most devastating among closely spaced plants such as bunching onions (those grown for their foliage) and less so among plants spaced more widely, such as bulb onions (those grown for bulb production, Coley-Smith and Esler, 1983; Scott, 1956).

Differences in levels of white rot incidence have been found among cultivars in field experiments (Coley-Smith and Esler, 1983; Hovius and McDonald, 1998; Utkhede and Rahe, 1978). Researchers disagree as to the significance of resistance among the cultivars. Coley-Smith (1987) and Coley-Smith and Esler (1983) argue that resistance among onions was only significant when disease levels were high resulting in a greater separation of average disease incidence between susceptible and resistant onions in statistical analysis. The question remains as to whether heritable white rot resistance exists within onions, since definitive proof has not been shown. Even though under high disease pressures none of the cultivars assessed by Coley-Smith and Esler (1983), Hovius and McDonald (1998), and Utkhede and Rahe (1978) were completely resistant to white rot infection, the possibility of using onion white rot resistance as a method of disease control has not been discounted.

Field trial assessments of white rot resistance have yielded less than satisfactory results, and it is clear that other screening techniques need to be developed. Earnshaw et al. (2000) developed a protocol for white rot screening based on a technique 
developed for screening onions for resistance to Botrytis infection (Miyaura et al., 1985). This technique makes use of onion scale inoculation as a method for determining differences in resistance among cultivars. Scales (leaves comprising layers of the onion bulb) are inoculated on the concave side and lesions develop and can be seen on the convex side. Scale segments from different onion cultivars were inoculated with actively growing white rot mycelium from two $S$. cepivorum mycelial compatibility groups (MCGs) (Earnshaw et al., 2000). Lesion diameter correlated significantly with field disease incidence of at least some of the same cultivars (Earnshaw et al., 2000). Scale inoculation could be used as a technique for initial screening, but it only takes into account putative tissue resistance and avoids the root and root organosulfur exudate complex that plays a role in stimulating the sclerotia to germinate.

Breeding crops for disease resistance is difficult when reliable and consistent techniques for screening germplasm do not exist. Without a reliable screen, it could take many years before an onion cultivar with economical levels of white rot resistance is released to the market. The objective of this research was to evaluate several techniques for screening long-day onions for white rot resistance.

\section{Material and Methods}

Plant material. Eight different long-day onion breeding lines and hybrids representing a range of reactions to white rot and one cultivar each of leek and garlic were assessed in the field, greenhouse and laboratory for their reaction to $S$. cepivorum (Table 1).

Field SCREening. Onions and leek at the second leaf stage were transplanted into fields on onion farms naturally infested with S. cepivorum in 2000 and 2001 in the Holland Marsh, Ontario, Canada (two different field sites per year) and seeded in 1999 and 2000 (one site per year but two different field sites) in Franklin District, Pukekohe Region, New Zealand. Both field sites consisted of soil high in organic matter $(>30 \%)$. Each onion and leek was replicated four times in a randomized complete block design. In the field sites in Canada, each replication consisted of one three $\mathrm{m}$ row, with 25 plants $/ \mathrm{m}$ within the row and $30 \mathrm{~cm}$ between rows. In the field sites in New Zealand, each replication consisted of one five $\mathrm{m}$ row, with 30 plants/m within the row

Table 1. Allium type, accession identifier, and source used in developing a screen for resistance to Sclerotium cepivorum.

\begin{tabular}{lccc}
\hline Common name & Accession & Type $^{\mathrm{z}}$ & Sourcey \\
\hline Onion*x & $1416 \mathrm{C}$ & $\mathrm{B}$ & $\mathrm{S}$ \\
Onion & $1247 \mathrm{~B}$ & $\mathrm{~B}$ & $\mathrm{~S}$ \\
Onion & Ricochet & $\mathrm{H}$ & $\mathrm{S}$ \\
Onion* & $1415 \mathrm{C}$ & $\mathrm{B}$ & $\mathrm{S}$ \\
Onion* & $\mathrm{W} 461 \mathrm{~B}$ & $\mathrm{~B}$ & $\mathrm{UW}$ \\
Onion* & $\mathrm{XPH} 15056$ & $\mathrm{H}$ & $\mathrm{S}$ \\
Onion* & $\mathrm{XPH} 15055$ & $\mathrm{H}$ & $\mathrm{S}$ \\
Onion* & $\mathrm{XPH} 15073$ & $\mathrm{H}$ & $\mathrm{S}$ \\
Leek & Ramona & $\mathrm{H}$ & $\mathrm{BS}$ \\
Garlic & RG9902 & $\mathrm{C}$ & $\mathrm{RF}$ \\
\hline
\end{tabular}

${ }^{\mathrm{z}} \mathrm{B}=$ breeding line, $\mathrm{H}=$ hybrid, $\mathrm{C}=$ clone.

y $\mathrm{S}=$ Seminis Vegetable Seeds, UW = breeding line from University of Wisconsin onion breeding program, BS $=$ Bejo Seeds and RF $=$ Roger's Food Inc.

${ }^{x}$ All the onion accessions followed by an asterisk contain 'Zittauer Gelbe'.

in their pedigree (a putative white rot resistant plant introduction from Germany). and $30 \mathrm{~cm}$ between rows. Recommended control procedures for pathogens, weeds and insects were followed and administered by the grower. In total, 50 to 100 onion bulbs and leek pseudostems were assessed at harvest for symptoms of disease from each $\mathrm{Al}$ lium per block. The number of onion and leek plants assessed per block differed within and among field sites since plant density, seed germination and loss due to other pests and pathogens differed among sites. Plants were pulled from the ground and those that had visible white rot mycelium and or sclerotia on the roots, bulbs or pseudostems (leek) were scored as white rot infected. If there were any doubt as to whether visible symptoms seen were white rot induced, the fungal structures were cultured in the lab for confirmation. Disease incidence $(\%)$ at all sites was calculated by dividing the number of white rot infected plants by the total number of plants assessed.

Production of S. cepivorum sclerotia. Potato dextrose agar (PDA) plates were inoculated with sclerotia of S. cepivorum. Sclerotia from mycelial compatibility group one (MCG-1) were collected from onion bulbs from a commercial onion production field located in the Holland Marsh, Ontario, Canada. The isolate was confirmed as MCG-1 by culturing against known isolates of MCG-1, MCG-2, and MCG-3. No discontinuity in the isolate culture was seen when cultured against MCG-1 but discontinuity appeared as a strip of thin, sparse mycelium between the isolate culture and MCG-2 and MCG-3. Mycelium from actively growing cultures were used to inoculate onion bulbs to produce sufficient sclerotia for the greenhouse screening trial; sclerotia production media other than onion bulbs had been previously tested (data not shown). Mycelium in S. cepivorum cultures is considered to be actively growing as long as the hyphae has not reached the culture plate wall. In culture, contact with the plate wall triggers the intiation of sclerotia production (Littley and Rahe, 1991). The sclerotia were produced in the laboratory on onion bulbs in 2001 as described by Coley-Smith (1985). Onion bulbs were surface sterilized for five minutes in $10 \%$ bleach, rinsed twice with sterile water and air dried in a laminar flow hood for $30 \mathrm{~min}$. Four flaps $\approx 0.8 \mathrm{~cm}$ deep (two to three scales deep), and $1.5 \mathrm{~cm}^{2}$ were cut in the basal portion of each bulb. Under each flap a $0.8 \mathrm{~cm}^{2}( \pm 0.1$ $\mathrm{cm}^{2}$ ) portion was removed. A $0.7-\mathrm{cm}$ core of an actively growing S. cepivorum culture was placed mycelium-side down under the flap. Parafilm was wrapped around the base of the bulb. Bulbs (basal plate up) were pushed into sterilized moistened perlite (3 $\mathrm{cm}$ deep) in plastic boxes that were $15 \mathrm{~cm}$ in height, and stored in the dark at room temperature. After $7 \mathrm{~d}$, the parafilm was removed. The bulbs were placed back in the dark for an additional 8 weeks. Sclerotia were collected by washing and wet sieving the onion tissue with sterile water. Five grams of sclerotia were harvested yielding $\approx 115,000$ sclerotia. They were air dried for $30 \mathrm{~min}$ and stored, in the dark glass jars for three months before use to break constitutive dormancy. Before use, two subsamples of 100 sclerotia each, were tested for viability. The percent viability of the sclerotia was $85 \%$. Sclerotia were considered viable if they germinated within $14 \mathrm{~d}$ after placement on PDA media. Germination was confirmed when mycelium was visible radiating away from the sclerotia.

Greenhouse SCREENING. All the alliums listed in Table 1 were screened for white rot resistance in the greenhouse. Muck soil was collected from a commercial vegetable production field in Wisconsin in the fall of 2001 and stored at room temperature until use. All soil was pushed through screens (pore size $0.2 \mathrm{~mm}^{2}$ ) and then half of the muck soil was steam sterilized. The muck soil was sterilized by autoclaving for $30 \mathrm{~min}$ at $121^{\circ} \mathrm{C}$. Plug trays 

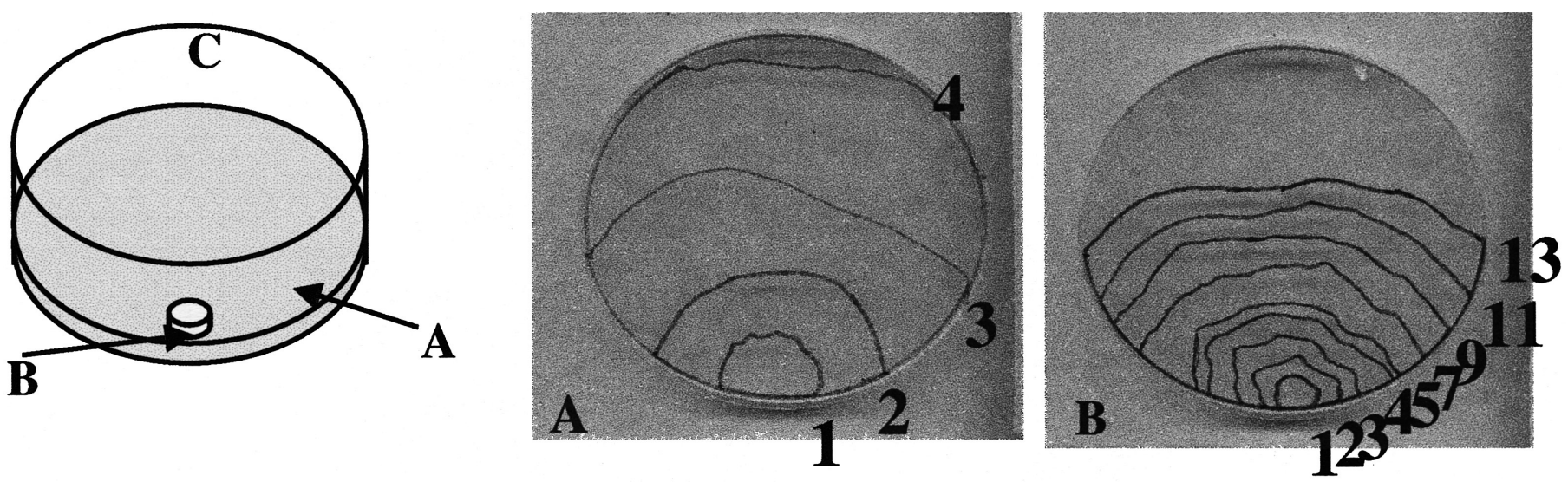

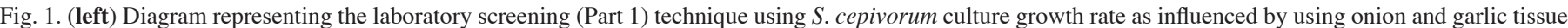

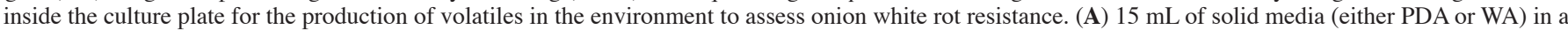
$150 \times 15$ mm culture plate, $(\mathbf{B}) 5$-cm core of actively growing $S$. cepivorum mycelium placed mycelium side down on media. (C) location inside petri dish where onion or garlic bulb tissue was taped to the lid but not touching the media. (right) The outlines of the growth of an S. cepivorum culture in the control that contained no Allium tissue, on (A) potato dextrose agar and (B) water agar. Next to each drawn line is the number of days post-inoculation that the culture area refers to.

(200 cell, $5.08 \mathrm{~cm}$ deep) were filled with either nonsterilized muck soil (NSMS) or sterilized muck soil (SMS). Depressions made in the soil of each cell were $\approx 1 \mathrm{~cm}$ deep. Six S. cepivorum sclerotia were placed in each cell. Crowe et al. (1980) stated that only a few sclerotia ( 2 to $6 \mathrm{~L}$ of soil) are necessary to yield $10 \%$ to $100 \%$ crop loss on nonorganic soils. About $20 \mathrm{~mL}$ of organic soil was contained within each plug and according to Crowe et al. (1980), using nonorganic soil 0.12 sclerotia would be needed per plug to achieve $100 \%$ infection. The garlic cloves were planted in $48 \mathrm{cell}, 5.08 \mathrm{~cm}$ deep plug trays. All alliums were replicated four times in a randomized complete block design and thinned to one plant per plug 2 weeks after germination for a total of 64 onion (per accession) and leek plants and 48 garlic plants per block. A 100 ppm 20N-7P-20K soluble fertilizer (TechniGrow) containing $1.4 \%$ sulfur was applied at $5 \mathrm{~mL} /$ plant at 7,11 , and 15 weeks after emergence. Plants were fertilized to facilitate normal plant growth. Soil was kept moist in the top $1 \mathrm{~cm}$ below the surface. Average day temperatures were $>26^{\circ} \mathrm{C}$ and night temperatures were $>24^{\circ} \mathrm{C}$. Nine weeks after emergence all wilted alliums were removed and assessed for white rot symptoms. Eighteen weeks after emergence all remaining alliums were harvested and assessed as described above in the field screening trial.

Laboratory screening, Part 1: S. cepivorum CUlture Growth RATE. Disposable, polystyrene, sterile culture plates $(100 \times 15$ mm, Falcon, Lincoln Park, N.J.) containing $15 \mathrm{~mL}$ PDA or 15 $\mathrm{mL}$ water agar (WA) were inoculated with one $5-\mathrm{cm}$ core of an actively growing $S$. cepivorum (MCG-1) culture by placing the core, mycelium side down, against the culture plate wall but on top of the media (Fig. 1). A2.0- $\mathrm{cm}^{2}$ piece of the seventh scale leaf (counted from the outside of the bulb) of an onion bulb or garlic clove was attached to the lid of the culture plate using sterilized surgical tape. Leek was not used in the tests. The seventh scale was chosen since it was the scale that needed the least amount of chopping to obtain an intact $2.0-\mathrm{cm}^{2}$ piece. The bulbs used were fresh. The lid was placed on the plate so that the bulb tissue was directly across from the culture core and not touching the media. All accessions were replicated four times in a randomized complete block design with each block stored in the dark at room temperature in a different location in the laboratory. A control containing no Allium tissue but with surgical tape on the lid was included in each block. The culture area was measured beginning one day postinoculation and continuing every $24 \mathrm{~h}$ up to $5 \mathrm{~d}$ by outlining the edge of the culture on the bottom of the culture plate using a permanent marker (Fig. 1). After $5 \mathrm{~d}$, the culture area was measured every $2 \mathrm{~d}$ up to $13 \mathrm{~d}$. The area at each measurement time was calculated using the public domain NIH Image program (http://rsb.info.nih.gov/nih-image/). Growth rate was calculated by dividing the area by the number of days postinoculation. The entire experiment was repeated one month later.

Laboratory screening, Part 2: S. cepivorum Culture aerial MYCELIA HEIGHT. Disposable, polystyrene, sterile culture plates $(35 \times 10 \mathrm{~mm}$, Falcon, Lincoln Park, N.J.) filled to the top with PDA were inoculated with 15 -cm core of an actively growing $S$. cepivorum (MCG-1) culture by placing the core, mycelium side down, in the center of the medium (Fig. 1). About $2 \mathrm{~g}$ of frozen onion or leek root tissue was placed in the lid of the culture plate and attached open side down to the inside lid of a Magenta GA7 culture vessel (Magenta Corp. Ill.). Garlic was not used since there was no frozen root tissue available. The culture plate containing the S.cepivorum culture was placed inside the box. All accessions were replicated four times in a randomized complete block design with each block stored in a different location on the laboratory bench at room temperature. The Magenta GA7 culture vessels were taped down to the laboratory bench to avoid movement and were covered with aluminum foil so that the cultures would be in complete darkness. A control containing no Allium tissue but with a culture plate lid and surgical tape securing it to the Magenta GA7 lid was included in each block. Two days postinoculation the S.cepivorum mycelium had grown across the entire culture plate. Aerial mycelium was observed in some of the onions $2 \mathrm{~d}$ postinoculation. We were concerned that at some point gravity would take effect and result in the aerial mycelium falling down. Therefore at $8 \mathrm{~d}$ postinoculation the height of the aerial mycelium was measured by placing a ruler against all four sides of the box and taking the height of the tallest hyphae that was not growing up the Magenta GA7 culture vessel wall. The four measurements were averaged to give an average height per Allium per block.

StatistiCal analysis. All data were analyzed using the SAS system for Mixed models (Littell et al., 1996). Data were tested for normality and transformed logarithmically to improve normality before analysis. Allium entry (all screening trials), site (field screening trial), and time (culture growth rate trial) were analyzed as fixed effects and block (all screening trials) and all country and block interactions (field screening trial) were analyzed as random effects. 
To determine if the results from the greenhouse and laboratory screening trials could be used to predict onion white rot reaction in the field, a covariance analysis was used. The logarithmically transformed disease incidence data from the field screening trial were used as the white rot reaction of the onion accessions. The field disease incidence data were not averaged over accessions or sites, but each value within each site was used in the analysis. The greenhouse disease incidence and laboratory screening results (dependent variables) used as the predictor were averaged over replications for each onion accession before use in the covariance analysis. Only those dependent variables that significantly discriminated among accessions were used in the covariance analysis and were tested as predictors for each field site separately. If the $P$ value of the dependent variable covariate effect was significant $(P \leq 0.05)$, and the $P$ value of the dependent variable $\times$ onion accession was less significant, then a particular dependent variable was considered unconditionally predictive of field disease incidence because the prediction was not based on prior knowledge of onion white rot resistance ranking. In other words, if the interaction of the dependent variable $\times$ onion accession was stronger than the dependent variable alone, the analysis would have to take into account what the onion accession was and would not be able to predict disease incidence without a priori knowledge of the onion accessions. A correlation analysis between the field disease incidence data and the dependent variables would have been appropriate if the material had been uniform. Since it was suspected that the different accessions would respond differently depending on putative susceptibility and resistance, the covariance analysis was used.

\section{Results}

Leek had the lowest disease incidence in the field $(1.3 \%$ averaged over all field sites) and greenhouse (26\% and $1 \%$ in
NSMS and SMS, respectively) screening trials and garlic had the highest disease incidence (79\% and 64\% in NSMS and SMS respectively) in the greenhouse screening trial. Our results ranked garlic as the most susceptible to white rot followed by onion and then leek, which agrees with results from other researchers (Coley-Smith, 1986; Coley-Smith and Esler, 1983; Coley-Smith et al., 1968). Since garlic and leek behaved as expected, they will not be discussed further. In all cases where probability values for determining significance are not noted, $P \leq 0.05$.

FieLD SCREENING. Within each field site, there was no significant correlation between the total number of plants assessed and white rot incidence. Sites within each country location were analyzed separately since the onion $\times$ site interaction was significant (Table 2). Disease incidence (\%) averaged across replicates was moderate (4 to 14 , site 1 ) to low ( 2 to 9 , site $2 ; 0.3$ to 9 , site $3 ; 0.5$ to 7 , site 4 ) in the Canadian field sites and high (9 to 100 , site 5 ) and moderate (3 to 15 , site 6 ) in the New Zealand field sites (Table 3). White rot disease symptoms were detected in every accession at every site. Significant differences among the onions were found at all sites except site 2 (Table 2).

GREENHOUSE SCREENING. Even though the interaction of soil treatment by onion accession was not significant, white rot incidence was analyzed separately for each soil treatment (NSMS and SMS) since there was significantly more disease in the NSMS treatment than the SMS treatment (Table 4). Total white rot incidence ranged from $28.5 \%$ to $54.7 \%$ in NSMS and $4.7 \%$ to $23.4 \%$ in SMS (Table 5). Significant differences among onions were found in NSMS at the second assessment date (18 weeks after emergence) and in total disease incidence and in SMS in total disease incidence (Table 5).

Laboratory screening, Part 1: S. cepivorum Culture Growth RATE. The average growth rate of $S$. cepivorum cultures on PDA as influenced by onion and garlic volatiles was not significantly different from the control containing no Allium tissue (data not

Table 2. F values from the analysis of variance of field white rot incidence in six sites over 3 years.

\begin{tabular}{|c|c|c|c|c|c|c|c|c|c|}
\hline & \multicolumn{9}{|c|}{ F value } \\
\hline & \multirow{2}{*}{$\begin{array}{c}\text { Both } \\
\text { countries }\end{array}$} & \multicolumn{5}{|c|}{ Canada } & \multicolumn{3}{|c|}{ New Zealand } \\
\hline & & Site 1 & Site 2 & Site 3 & Site 4 & All sites & Site 5 & Site 6 & All sites \\
\hline Onion accession & $5.9^{* * *}$ & $3.1^{* *}$ & 1.3 & $6.2^{* * *}$ & $4.2^{* * *}$ & $4.0^{* * *}$ & $28.0^{* * * *}$ & $11.5^{* * * *}$ & $17.6^{* *}$ \\
\hline Site & $40.2^{* * * *}$ & & & & & $11.9^{* * * *}$ & & & $122.3^{* * *}$ \\
\hline Onion accession $\times$ site & $4.1^{* * *}$ & & & & & $5.8^{* *}$ & & & $23.1^{* * *}$ \\
\hline
\end{tabular}

***,*** Significant at $P \leq 0.10,0.05$, or 0.01 , respectively.

Table 3. Field white rot screening results from two countries, including six sites in 1999, 2000 and 2001 comparing the average disease incidence (percent, calculated using least squared means) of eight onion accessions.

\begin{tabular}{|c|c|c|c|c|c|c|}
\hline \multirow[b]{3}{*}{ Accession } & \multicolumn{6}{|c|}{ Field white rot incidence (\%) } \\
\hline & \multicolumn{4}{|c|}{ Canada } & \multicolumn{2}{|c|}{ New Zealand } \\
\hline & Site 1 & Site 2 & Site 3 & Site 4 & Site 5 & Site \\
\hline 1416C & 8.8 & 5.4 & 0.9 & 2.1 & 100.0 & 5.7 \\
\hline 1247B & 9.9 & 4.0 & 8.8 & 1.1 & 91.3 & 14.9 \\
\hline Ricochet & $---z$ & --- & 1.8 & 6.5 & --- & --- \\
\hline $1415 \mathrm{C}$ & 4.6 & 2.1 & 5.5 & 0.5 & 17.3 & --- \\
\hline W461B & 4.1 & 2.3 & 0.3 & 0.5 & --- & --- \\
\hline XPH15056 & 6.1 & 5.2 & 2.5 & 0.8 & 9.8 & 5.1 \\
\hline XPH15055 & 13.9 & 6.6 & 0.4 & 1.1 & --- & 6.0 \\
\hline XPH15073 & --- & --- & 2.5 & 3.2 & 14.0 & 4.2 \\
\hline $\operatorname{LSD}_{(0.05)}$ & 4.0 & 3.3 & 1.4 & 1.9 & 7.2 & 2.3 \\
\hline $\operatorname{LSD}_{(0.01)}$ & 5.6 & 4.5 & 1.9 & 2.6 & 10.1 & 3.2 \\
\hline Disease level & Moderate & Low & Low & Low & High & Moderate \\
\hline
\end{tabular}

zMissing. 
Table 4. $F$-values from the analysis of variance of fixed effects on greenhouse white rot incidence at nine and 18 weeks after emergence and total ( 9 and 18 weeks) in two soil treatments (Soil), nonsterile muck soil (NSMS) and sterile muck soil (SMS).

\begin{tabular}{|c|c|c|c|c|c|c|c|c|c|}
\hline \multirow[b]{4}{*}{ Source of variation } & \multicolumn{9}{|c|}{ F values } \\
\hline & \multicolumn{3}{|c|}{9 weeks postemergence } & \multicolumn{3}{|c|}{18 weeks postemergence } & \multicolumn{3}{|c|}{ Total } \\
\hline & \multicolumn{3}{|c|}{ Muck soil treatment } & \multicolumn{3}{|c|}{ Muck soil treatment } & \multicolumn{3}{|c|}{ Muck soil treatment } \\
\hline & NSMS & SMS & Both & NSMS & SMS & Both & NSMS & SMS & Both \\
\hline Onion accession & $0.1^{* *}$ & 1.8 & 1.7 & $3.2^{* *}$ & 2.0 & $2.6^{* *}$ & $4.1^{* *}$ & $2.78^{* *}$ & $2.6^{* * *}$ \\
\hline Soil & & & $91.7^{* * *}$ & & & $6.4^{* *}$ & & & $89.8^{* * *}$ \\
\hline Onion accession $\times$ soil & & & 1.5 & & & 1.3 & & & 1.5 \\
\hline
\end{tabular}

$\overline{* * * * * * * *}$ Significant at $P \leq 0.10,0.05$, or 0.01 , respectively.

Table 5. Greenhouse white rot screening results from non-sterile (NSMS) and sterilized (SMS) field muck soil comparing the average disease incidence (\%, calculated using least squared means) of eight onion accessions.

\begin{tabular}{|c|c|c|c|c|c|c|}
\hline \multirow[b]{4}{*}{ Accession } & \multicolumn{6}{|c|}{ Greenhouse white rot incidence (\%) } \\
\hline & \multicolumn{3}{|c|}{ NSMS } & \multicolumn{3}{|c|}{ SMS } \\
\hline & \multicolumn{3}{|c|}{$\begin{array}{l}\text { Time after plant emergence } \\
\text { (weeks) }\end{array}$} & \multicolumn{3}{|c|}{$\begin{array}{l}\text { Time after plant emergence } \\
\text { (weeks) }\end{array}$} \\
\hline & $9^{z}$ & 18 & Total & 9 & 18 & Total \\
\hline 1416C & 39.8 & 14.8 & 54.7 & 13.3 & 2.0 & 15.2 \\
\hline 1247B & 42.6 & 10.2 & 52.7 & 14.5 & 4.3 & 18.8 \\
\hline Ricochet & 28.1 & 8.6 & 36.7 & 7.4 & 2.7 & 10.2 \\
\hline $1415 \mathrm{C}$ & 39.5 & 7.4 & 46.9 & 7.0 & 2.0 & 9.0 \\
\hline W461B & 21.9 & 5.5 & 27.3 & 20.3 & 3.1 & 23.4 \\
\hline XPH15056 & 31.6 & 3.5 & 35.2 & 4.3 & 0.4 & 4.7 \\
\hline XPH15055 & 29.7 & 8.2 & 37.9 & 12.5 & 2.3 & 14.8 \\
\hline XРH15073 & 25.0 & 6.6 & 31.6 & 4.2 & 0.6 & 4.7 \\
\hline $\mathrm{LSD}_{0.05)}$ & 11.2 & 6.9 & 12.3 & 16.2 & 4.1 & 9.2 \\
\hline $\operatorname{LSD}_{(0.01)}$ & 16.2 & 9.6 & 19.8 & 21.6 & 5.3 & 12.4 \\
\hline
\end{tabular}

${ }^{2}$ Disease incidence assessed nine and 18 weeks after plant emergence.

shown). The S. cepivorum cultures on PDA at 4 d postinoculation reached the edge of the culture plate. The cultures on PDA containing onion and garlic tissue and therefore exposed to volatiles from those tissues, produced aerial mycelium, but no aerial mycelium was noted in the control treatments (Fig. 1). The average growth rate of the $S$. cepivorum cultures on WA were significantly slower than the PDA and most of the cultures did not reach the edge of the culture plates until $13 \mathrm{~d}$ postinoculation. The S. cepivorum mycelium on WA was much sparser than on PDA. Culture growth rate on WA increased over time, but after $\approx 9 \mathrm{~d}$ some of the cultures showed steady growth rates (Fig. 1). The control had significantly slower growth rates regardless of when the culture area was measured.

Laboratory SCReening, Part 2: S. cepivorum CULTURE AERIAL MYCELIA HEIGHT. Aerial mycelium was observed in all cultures including the control (Fig. 1). The average aerial mycelial height among the onions ranged from 8.3 to $12.6 \mathrm{~mm}$ before the mycelium fell (Table 6). The control had a significantly shorter mycelial height $(5.2 \mathrm{~mm})$ than leek $(6.5 \mathrm{~mm})$ and the onions. The mycelial heights were recalculated as a percentage of the

Fig. 2. Average growth rate (calculated using least squared means) of $S$. cepivorum cultures on water agar media, comparing cultures containing groupings of susceptible $(\mathrm{SBH})$ and resistant $(\mathrm{RBH})$ onion bulb tissue, based on field reaction, garlic or a control with no alliums. Data points within an ellipse were not significant from each other at $P$ $\leq 0.05$ within day postinoculation. control treatment and in this study all alliums were greater than the control.

Predicting field disease using greenhouse disease inCIDENCE, CULTURE GROWTH RATES, AND CULTURE AERIAL MYCELIUM HEIGHTS. The dependent variables from the greenhouse and laboratory screening trials that resulted in significant differences
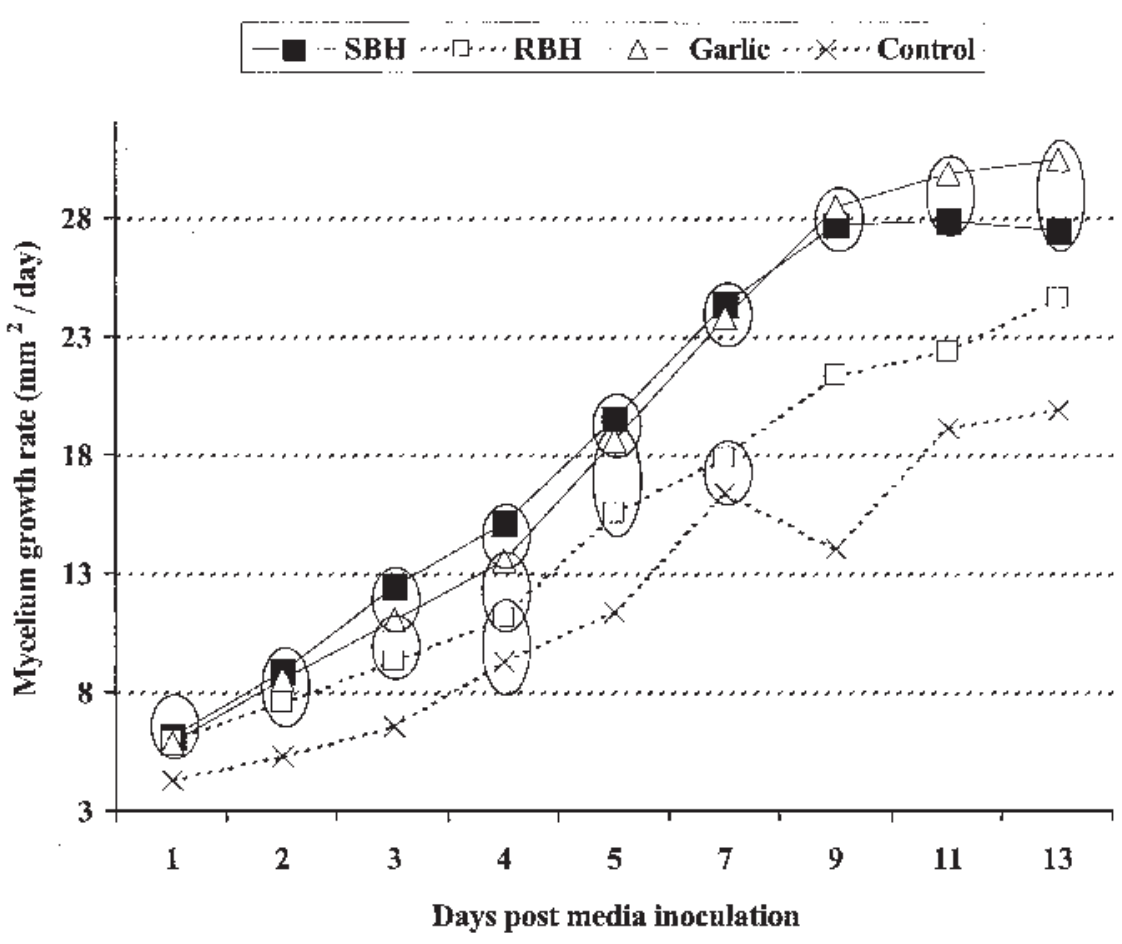


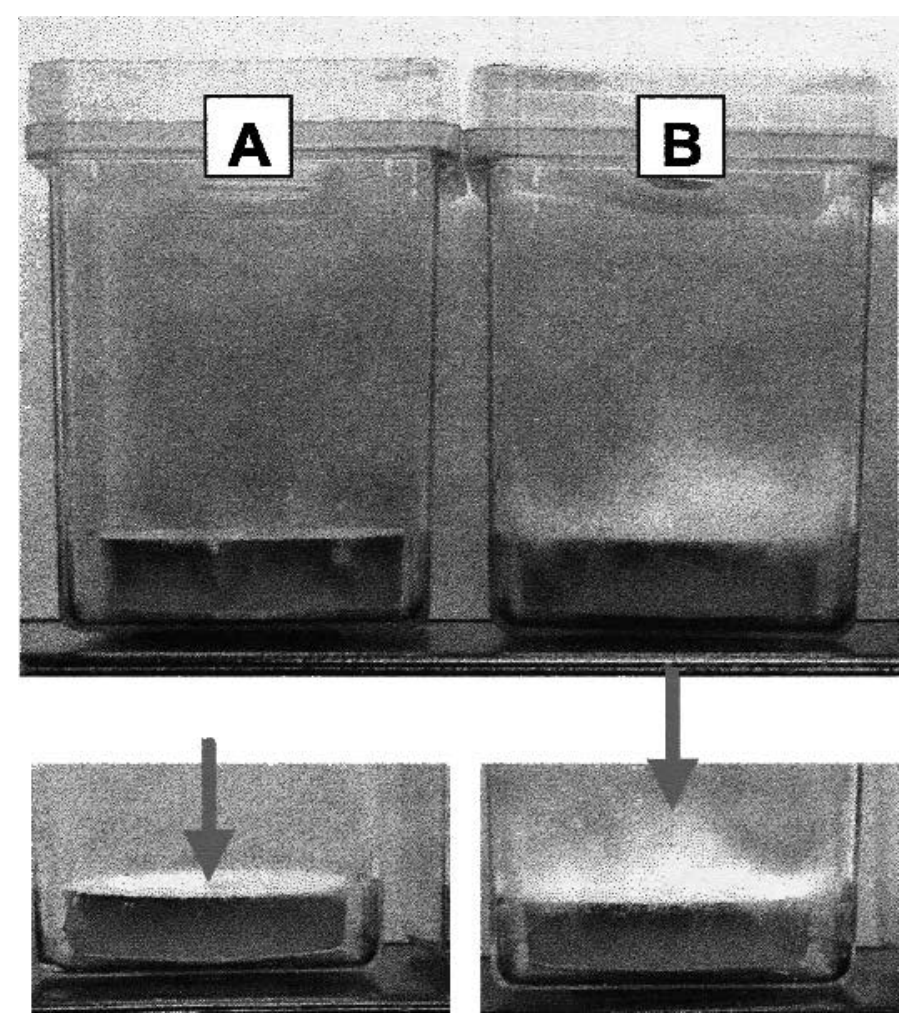

Fig. 3. S. cepivorum aerial mycelial height, (A) aerial mycelium was very short in the control containing no Allium root tissue, arrow pointing to approximate height of mycelium and (B) significantly higher in all cultures containing susceptible onion root tissue, arrow pointing to approximate height of mycelium.

Table 6. The effect of onion and leek root volatiles on the average height (calculated using least squared means) of aerial S. cepivorum mycelium growing in culture, a control containing no Allium tissue was also included.

\begin{tabular}{lcc}
\hline & \multicolumn{2}{c}{ S. cepivorum mycelium } \\
\cline { 2 - 3 } Accession & $\mathrm{Ht}(\mathrm{mm})$ & Percent greater than control \\
\hline 1416C & 11.4 & 219 \\
1247B & 12.6 & 242 \\
Ricochet & 11.5 & 221 \\
1415C & 9.0 & 173 \\
W461B & 8.6 & 165 \\
XPH15056 & 7.6 & 146 \\
XPH15055 & 8.6 & 165 \\
XPH15073 & 8.3 & 157 \\
Leek & 6.5 & 125 \\
Control & 5.2 & $\mathrm{NA}$ \\
LSD $_{(0.05)}$ & 2.1 & 70.1 \\
LSD $_{(0.01)}$ & 2.8 & 86.7 \\
\hline
\end{tabular}

among entries were used in the covariance analysis. Those that predicted field disease incidence are shown in Table 7. The best predictor of field disease incidence was the dependent variable that significantly predicts disease incidence for the greatest number of field sites but also has a more significant $P$ value than the dependent variable $\times$ onion interaction. The $P$ value differences are important when determining effectiveness of the dependent variable as a field disease incidence predictor. If the $P$ value of the interaction term is similar to the $P$ value of the covariate effect, then the dependent variable is only predictive of white rot reaction within different onion field disease incidence groupings and not among the eight onion accessions used in this study. Disease incidence in the greenhouse, $S$. cepivorum culture growth rates on WA media and aerial mycelial height were all good predictors of field disease incidence. Based on the criteria described above, the best predictor of field disease incidence from the greenhouse screening trial was the total white rot incidence from the NSMS. The best predictor of field disease incidence from the culture growth rate screening trial was the growth rates measured $7 \mathrm{~d}$ postinoculation in WA. The best predictor overall was from the aerial mycelium screening trial. The aerial mycelium height as a percentage of the control was able to predict field disease incidence in four out of six field sites, including field sites with low, moderate and high disease incidence.

\section{Discussion}

A number of studies have shown that significant differences among onion cultivars can be detected in field screening (ColeySmith et al., 1987; Hovius and McDonald, 1998; Utkhede and Rahe, 1978). In our study, differing levels of disease (low, moderate and high) developed among the field sites. However, the results also demonstrate the difficulty in obtaining high white rot disease levels consistently over years and sites. This was shown both by the differing disease levels found among the field sites and the fact that the onion accession $\times$ field site was significant. Unfavorable environmental conditions for disease development (hot and dry) resulted in low disease levels and made statistical comparisons difficult among onions in previous studies (Hovius and McDonald, 1998).

White rot occurs in disease foci in fields and it is sometimes difficult to determine where the disease foci are located for placement of the field trials. No information exists on the spatial distribution of $S$. cepivorum sclerotia in muck soil. Missing the disease foci in the field sites may have resulted in low disease levels in three out of six sites. Differences in resistance may also occur among different seed lots of the same cultivar (Utkhede and Rahe, 1984). Another reason for the significant onion accession $\times$ field site interaction could be explained by the fact that not all of the MCGs among New Zealand and Canada are the same and different MCGs may have existed among locations within countries. $\mathrm{pH}$ is known to influence the persistence of the volatile products the ACSO alliinase reaction (personal communication, Kirk Parkin, Univ. Wisconsin, Dept. of Food Science). Lee and Parkin (1998) found that as the $\mathrm{pH}$ decreased from 6.1 to 3.2 in onion extracts the abundance and persistence of thiosulfinates decreased.

Screening in the greenhouse was accomplished in nonsterile muck soil (NSMS) to simulate field soil environments and in sterile muck soil (SMS) to try to evaluate tissue resistance apart from the ability of the onions to stimulate sclerotia to germinate. In sterile culture or soil, $S$. cepivorum sclerotia past constitutive dormancy will germinate in the absence of Allium organosulfur root exudates. Therefore, in the SMS treatment, sclerotia should germinate sooner than in the NSMS since the seeds need to germinate and exude organosulfur exudates in the NSMS in order to stimulate the sclerotia to germinate.

Disease incidence in the SMS treatment may have been lower than expected based on the relationship between $S$. cepivorum sclerotia, Allium organosulfur compounds and the hypothesized role of soil microorganisms. Although not well studied, it is possible that microorganisms in the NSMS treatment aided in the conversion of the root organosulfur compounds to volatile organosulfur compounds necessary for stimulation of sclerotial germination (Reddy et al., 1992; Reddy and Rahe, 1987). 
Table 7. Dependent variables (greenhouse disease incidence - GDI, Sclerotium cepivorum mycelium growth rate in culture in days post-inoculation (MGR) and aerial mycelial height (MH) as affected by onion plant organ volatiles) that significantly predicted field disease incidence, by field site in a covariance analysis.

\begin{tabular}{|c|c|c|c|c|c|}
\hline \multirow{2}{*}{$\begin{array}{l}\text { Screening } \\
\text { trial }\end{array}$} & \multirow{2}{*}{$\begin{array}{l}\text { Dependent } \\
\text { variable }\end{array}$} & \multirow{2}{*}{$\begin{array}{c}\text { No. of field } \\
\text { sites predicted }\end{array}$} & \multirow{2}{*}{$\begin{array}{l}\text { Disease level } \\
\text { of field sites }\end{array}$} & \multicolumn{2}{|c|}{$P$ valuey } \\
\hline & & & & Covariate & Covariate $\times$ onion \\
\hline \multirow[t]{5}{*}{$\overline{\mathrm{GDI}}(\%)$} & Nonsterile muck soil & & & & \\
\hline & 18 weeks after plant emergence & 1 & $\mathrm{H}$ & $* * *$ & $* *$ \\
\hline & Total disease incidence & 2 & $\mathrm{M}, \mathrm{H}$ & $* *$ & $*$ \\
\hline & Sterile muck soil & & & & \\
\hline & Total disease incidence & 3 & $\mathrm{M}, \mathrm{H}$ & $* *$ & $*$ \\
\hline \multirow[t]{5}{*}{ MGR } & $3 \mathrm{~d}$ & 2 & $\mathrm{~L}, \mathrm{H}$ & $* *$ & $*$ \\
\hline & $4 \mathrm{~d}$ & 2 & $\mathrm{~L}, \mathrm{H}$ & $* *$ & $*$ \\
\hline & $5 \mathrm{~d}$ & 1 & $\mathrm{H}$ & $* * *$ & $* *$ \\
\hline & $7 \mathrm{~d}$ & 3 & $\mathrm{~L}, \mathrm{M}, \mathrm{H}$ & $* * *$ & $* *$ \\
\hline & $9 \mathrm{~d}$ & 2 & M, H & $* *$ & $*$ \\
\hline \multirow[t]{2}{*}{ MH } & Height & 3 & $\mathrm{M}, \mathrm{H}$ & $* *$ & $*$ \\
\hline & $\%$ of control & 4 & $\mathrm{~L}, \mathrm{M}, \mathrm{H}$ & $* *$ & $*$ \\
\hline
\end{tabular}

${ }_{\mathrm{L}}=$ low, $\mathrm{M}=$ moderate, $\mathrm{H}=$ high.

********Covariance effect significant at $P \leq 0.05,0.01$, or 0.001 , respectively.

Therefore, the number of sclerotia that germinated in the NSMS treatment was higher than in the SMS treatment. Although not assessed in this study, volatiles other than organosulfur volatiles may have been important in sclerotial germination.

The mycelium exuding from the sclerotia that germinated before or during the early stages of onion seed germination in the SMS treatment may not have found the root tissue or sufficient root tissue to survive. Therefore, disease incidence may have been lower in the SMS treatment simply because the mycelium lacked a nutritional source. In contrast to field screening, environmental conditions optimum for disease development can be controlled in the greenhouse and therefore this is a more reliable technique.

Two laboratory-based techniques were used to screen for onion white rot resistance by testing culture growth rate and height of produced aerial mycelium as influenced by Allium volatile compounds. Allen and Young (1968), Coley-Smith and Holt (1966), Coley-Smith and King (1969), and King and Coley-Smith (1969) showed that the volatile organosulfur compounds that comprise flavor in alliums were responsible for sclerotial germination. We attempted to add Allium organosulfur compounds to the environment inside the culture container by placing Allium tissue inside the container but not touching the culture media. The respiration processes occurring within the Allium tissue would result in cellular breakdown. Therefore, reaction of alliinase and flavor precursors necessary for organosulfur compound production could occur. By not allowing contact of the Allium tissue and culture media there was little possibility of adding nutrition to the media, which might have influenced culture growth rate. The head space of the cultures, once opened, smelled distinctly as alliums are expected to smell and there was no smell in the cultures that did not contain Allium tissue. Since the headspace within the cultures was not analyzed for organosulfur compounds the compounds will be referred to as volatiles .

Sclerotium cepivorum culture growth rate, as influenced by onion bulb tissue volatiles, grew significantly faster when influenced by susceptible tissue than resistant tissue on WA. Under field conditions, profuse white mycelium develops and grows through the soil matrix up to $3 \mathrm{~cm}$ (Crowe and Hall, 1980) until contact with host tissue (Walker, 1924). If root infection does not occur within 10 to $14 \mathrm{~d}$, the mycelium from the germinated sclerotia dies and decays (Coley-Smith, 1960; Crowe and Hall, 1980). This means that the sclerotia contain a limited amount of nutrition for mycelial growth postgermination. The mycelium must locate the areas within the soil matrix where the Allium roots are present. It is possible that areas within the soil matrix where the Allium roots are present would have higher concentrations of organosulfur volatiles. Therefore it would be an evolutionary advantage for S. cepivorum mycelium to be able to detect and grow toward those areas of high organosulfur volatile concentration. In other words, chemotaxis may be the process by which $S$. cepivorum mycelium finds Allium roots.

Aerial mycelium of $S$. cepivorum is not normally seen in culture on PDA but was observed in the growth rate trial and a laboratory technique to measure height as a method of screening for resistance was developed and assessed. The height of $S$. cepivorum aerial mycelium in culture as influenced by onion root tissue volatiles was significantly higher in the susceptible than resistant tissues. Both laboratory methods were simple to set up and took no more than $14 \mathrm{~d}$ from start to finish. Aerial mycelium grew in the control containing no Allium tissue but it was significantly shorter than the cultures containing Allium tissue. We discovered the reason for the aerial mycelium in the control once the trial was underway. The culture plates were poured full of PDA media and inoculated with S. cepivorum. Mycelium in $S$. cepivorum cultures is considered to be actively growing as long as the hyphae has not reached the culture plate wall. In culture, reaching the wall triggers the intiation of sclerotia production (Littley and Rahe, 1991). As there was no wall in our trial set up and a nutrition source in the media, the mycelium in the control remained actively growing and therefore some of the mycelium grew up and some actually grew over the sides of the plates and grew down. In hindsight, this technique may have resulted in even greater differences among the alliums and control if the culture plates had not been poured full.

A covariance analysis was used to determine if the dependent variables measured in the greenhouse and laboratory screening trials that significantly distinguished between the susceptible and resistant accessions could be used to predict which onions would have a higher level of white rot incidence under field conditions. For disease incidence in the greenhouse, S. cepivorum culture growth rates on WA media and aerial mycelium height calculated as a percentage of the untreated control, were all good predictors of field disease incidence. From the greenhouse trial, the total disease incidence from the SMS treatment predicted three field 
sites as compared to one and two from the NSMS treatment (18 weeks after plant emergence and total disease incidence, respectively). The SMS treatment did not totally eliminate the possibility of organosulfur root exudates stimulating sclerotial germination since sclerotial germination is not simultaneous. Regardless, the SMS treatment was a better evaluation of any tissue resistance that may exist within the onion accessions used. The fact that the SMS treatment was a better predictor of onion accession field white rot reaction supports the hypothesis that onion white rot resistance may be partially due to putative tissue resistance.

The best predictor overall was from the aerial mycelium screening trial. The height of the aerial mycelium as a percentage of the control, successfully predicted field disease incidence in four out of six field sites, including field sites with low, moderate and high disease incidence. Therefore, the cultures that had the highest aerial mycelium contained tissues from the onion accessions that had the highest white rot incidences in the field.

If these screening techniques continue to reveal useful differences in onion germplasm, breeders may be able to use the methods described in this study. The greenhouse screening method using NSMS might be used to evaluate the potential field response of onion breeding lines and hybrids. The onions with the highest disease incidence in the greenhouse will most likely result in the highest disease incidence in the field. Although the methods discussed were not assessed on an individual plant basis, the laboratory methods evaluating culture growth rate and aerial mycelium height could be used screen large numbers of progeny from onion crosses before screening in the greenhouse and field.

\section{Literature Cited}

Abd-El-Razik, A.A., N.M. Shatla, and M. Rushdi. 1973. Studies on the infection of onion plants by Sclerotium cepivorum Berk. Phytopathologie Zeitschrift. 76:108-116.

Allen, J.D. and J.M. Young. 1968. Soil fungistasis and Sclerotium cepivorum Berk. Plant Soil 29:479-480.

Coley-Smith, J.R. 1960. Studies of the biology of Sclerotium cepivorum Berk. IV. Germination of sclerotia. Ann. Appl. Biol. 48:8-18.

Coley-Smith, J.R. 1985. Methods for the production and use of sclerotia of Sclerotium cepivorum in field germination studies. Plant Pathol. 34:380-384.

Coley-Smith, J.R. 1986. A comparison of flavor and odor compounds of onion, leek and garlic and Allium fistulosum in relation to germination of sclerotia of Sclerotium cepivorum. Plant Pathol. 35:370-376.

Coley-Smith, J.R. 1987. Alternative methods of controlling white rot disease of Allium, p. 161-177. In: I. Ched (ed.). Innovative approaches to plant disease control. Wiley, New York.

Coley-Smith, J.R. and R.W. Holt. 1966. The effect of species of Allium on germination in soil of sclerotia of Sclerotium cepivorum Berk. Ann. Appl. Biol. 58:273-278.

Coley-Smith, J.R., D.J. Dickinson, J.E. King, and R.W. Holt. 1968. The effect of species of Allium on soil bacteria in relation to germination of sclerotia of Sclerotium cepivorum Berk. Ann. Appl. Biol. 62: 103-111.

Coley-Smith, J.R. and J.E. King. 1969. The production by species of Allium of alkyl sulphides and their effects on germination of sclerotia of Sclerotium cepivorum Berk. Ann. Appl. Biol. 64:289-301.

Coley-Smith, J.R. and G. Esler. 1983. Infection of cultivars of onion, leek and garlic and Allium fistulosum by Sclerotium cepivorum. Plant Pathol. 32:373-376.

Crowe, F. and D.H. Hall. 1980. Soil temperature and moisture on sclerotial germination and infection of onion seedlings by Sclerotium cepivorum. Phytopathology 70:74-78.

Earnshaw, D.M., M.R. McDonald, and G.J. Boland. 2000. Interactions among isolates and mycelial compatibility groups of Sclerotium cepivorum and cultivars of onion (Allium cepa). Can. J. Plant Pathol. 22:387-391.

Hovius, M.H.Y. and M.R. McDonald. 1998. Screening onion lines for resistance to Sclerotium cepivorum using field and onion scale assessments. Proc. $6^{\text {th }}$ Intl. Wkshp. Allium white rot. Poster session. p. $5-10$.

King, J.E. and J.R. Coley-Smith. 1969. Production of volatile alkyl sulphides by microbial degradation of synthetic alliin and alliin-like compounds in relation to germination of sclerotia of Sclerotium cepivorum Berk. Ann. Appl. Biol. 64:303-314.

Lee, C.H. and K.L. Parkin. 1998. Relationship between thiosulfinates and pink discoloration in onion extracts, as influenced by $\mathrm{pH}$. Food Chem. 61:345-350.

Littell, R.C, G.A. Milliken, W.W. Stroup, and R.D. Wolfinger. 1996. SAS system of mixed models. SAS Inst., Cary, N.C.

Littley, E.R. and J.E. Rahe. 1991. In vitro initiation of sclerotia of Sclerotium cepivorum. Can. J. Plant Pathol. 13:45-49.

Miyaura, L, Y. Shinada, and W. A. Gabelman. 1985. Selection for resistance of onions to Botrytis allii by scale inoculation method. HortScience 20:769-770.

Perez-Moreno, L., V. Olalde-Portugal, J.G. Salina-Gonzalez, J.R. Sanchez-Pale, and A.R. Entwistle. 1998. Current known distribution of white rot Sclerotium cepivorum Berk in Mexico. Proc. $6^{\text {th }}$ Intl. Wkshp. Allium white rot. Geographical distribution of Allium white rot and economic effects. p. 6-9.

Reddy, M.S., J.E. Rahe, and C. Levesque. 1992. Influence of onion seed bacterization on germination and mycosphere microflora of Sclerotium cepivorum sclerotia. Can. J. Microbiol. 38:1135-1143.

Reddy, M.S. and J.E. Rahe. 1987. Effect of onion seed bacterization on the germination of sclerotia of Sclerotium cepivorum in muck soil. Phytopathology 77:1715-1718.

Scott, M.R. 1956. Studies of the biology of Sclerotium cepivorum Berk. I. Growth of the mycelium in soil. Ann. Appl. Biol. 44:576-583.

Sommerville, P. and D.H. Hall. 1987. Factors affecting sclerotial germination of Sclerotium cepivorum, secondary sclerotia formation and germination stimulants to reduce inoculum density. Plant Dis. 71: 229-233.

Stewart, A. and R.A. Fullterton. 1998. Geographic distribution and economic importance of Allium white rot in New Zealand. Proc. $6^{\text {th }}$ Intl. Wkshp. Allium white rot. Geographical distribution of Allium white rot and economic effects. p. 10-12.

Stewart, A., D. Backhouse, P. W. Sutherland, and R. A. Fullerton. 1989. The development of infection structures of Sclerotium cepivorum on onion. J. Phytopathol. 126:122-132.

Utkhede, R.S. and J.E. Rahe. 1978. Screening commercial onion cultivars for resistance to white rot. Phytopathology 68:1080-1083.

Utkhede, R.S. and J. E. Rahe. 1984. Resistance to white rot infections in bulb onion seed lots. Scientia Hort. 22:315-320.

Walker, J.C. 1924. White rot of Allium in Europe and America. Phytopathology 14:315-322. 